\title{
Lansoprazole provided more effective and faster relief for heartburn than omeprazole in erosive oesophagitis
}

Richter JE, Kahrilas PJ, Sontag SJ, et al. Comparing lansoprazole and omeprazole in onset of heartburn relief: results of a randomized, controlled trial in erosive esophagitis patients. Am J Gastroenterol 2001 Nov;96:3089-98.

\section{QUESTION: In patients with erosive oesophagitis, is lansoprazole better than omeprazole for relieving heartburn?}

\section{Design}

Randomised \{allocation concealed*\}†, blinded \{patients, clinicians, data collectors, outcome assessors, and data safety and monitoring committee $\} \nmid, *$ controlled trial with 8 week follow up.

\section{Setting}

162 clinical centres in the USA.

\section{Patients}

3510 patients who were $\geqslant 18$ years of age (mean age $47 y$, $57 \%$ men), had endoscopically confirmed erosive oesophagitis $\geqslant$ grade 2 , and had had $\geqslant 1$ episode of moderate to very severe heartburn during the previous 3 days or nights, or both. Exclusion criteria included duodenal or gastric ulcers $\geqslant 3 \mathrm{~mm}$ in diameter; systemic disease affecting the oesophagus; history of gastrointestinal bleeding or gastric, duodenal, or oesophageal surgery; and long term use of ulcerogenic drugs. $96 \%$ of patients completed the study.

\section{Intervention}

Patients were allocated to lansoprazole, $30 \mathrm{mg}(\mathrm{n}=1754)$, or omeprazole, $20 \mathrm{mg}(\mathrm{n}=1756)$, once daily before breakfast for 8 weeks.

\section{Main outcome measures}

Presence and severity (none [score 0] to very severe [score 4]) of daytime and night time heartburn, which were recorded in daily diaries.

\section{Main results}

More patients in the lansoprazole group than in the omeprazole group had no episodes of heartburn throughout the treatment period $(\{14 \%$ v $11 \%\} \dagger$ $\mathrm{p}<0.05)$ and were free of heartburn on day $1(33 \% v$ $25 \%, p \leqslant 0.001)$. The lansoprazole group had a greater percentage of heartburn free days (mean $66 \%$ v $62 \%$ of days, $\mathrm{p}<0.001$ ) and heartburn free nights (mean $69 \% v$ $64 \%$ of nights, $\mathrm{p}<0.001$ ) than the omeprazole group during week 1 . Severity of heartburn was lower in the lansoprazole group than in the omeprazole group during the day (mean severity score $0.46 v 0.53, \mathrm{p}<0.001$ ) and night (mean severity score $0.44 v 0.51, \mathrm{p}<0.001$ ) in week 1 .

\section{Conclusion}

In patients with erosive oesophagitis, lansoprazole was better than omeprazole for providing heartburn relief quickly.

*See glossary.

$\nmid$ Information provided by author.

\section{COMMENTARY}

Although proton pump inhibitors (PPIs) may differ in pharmacokinetic profiles, all are efficacious in the treatment of erosive oesophagitis. In a recent meta-analysis on the efficacy of different PPIs for the treatment of acute gastro-oesophageal reflux disease, ${ }^{1}$ no difference was found in rates of resolution of heartburn, ulcer healing, and relapse of symptoms when compared with placebo. These results are in accord with the general clinical experience with these drugs. Despite this finding, a competitive billion dollar pharmaceutical market fuels studies designed to directly compare the efficacy and pharmacokinetic profiles of various PPIs, with the resulting small differences being promoted to persuade physicians to change their prescription habits in favour of a particular drug.

In this head to head comparison of lansoprazole with omeprazole, Richter et al found lansoprazole to be more effective than omeprazole in eliminating heartburn after 1 dose as well as after 8 weeks of treatment. The authors suggest that this finding may be explained by the greater bioavailability of lansoprazole.

The authors are to be congratulated on putting together a large, well designed, and well executed study. However, are the results important? Although statistically significant, the differences between the 2 PPIs (especially beyond the first week) are clinically trivial: for instance, does it really matter if $56 \%$ of the lansoprazole group are heartburn free during the first 3 days compared with $49 \%$ of the omeprazole group when the average heartburn severity for both groups is $<1$ (mild) on a scale of 0 to 4 ? Or that sustained heartburn relief is obtained in $53 \%$ of the lansoprazole group compared with $51 \%$ of the omeprazole group? In fact, this study probably reinforces the argument that differences between the current generation of PPIs are irrelevant in today's healthcare environment in which the direct cost to the patient or the insurance plan, or both, has become the main factor in the PPI decision tree.

W A Hoogerwerf, MD $\mathrm{P}$ Jay Pasricha, MD University of Texas Medical Branch Galveston Texas USA

1 Caro JJ, Salas M, Ward A. Healing and relapse rates in gastroesophageal reflux disease treated with the newer proton-pump inhibitors lansoprazole, rabeprazole, and pantoprazole compared with omeprazole, ranitidine, and placebo: evidence from randomized clinical trials. Clin Ther 2001;23:998-1017. 